\title{
The role of seed priming in improving seedling growth of maize (Zea mays L.) under salt stress at field conditions
}

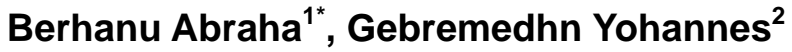 \\ ${ }^{1}$ Bahir Dar University, Bahir Dar, Ethiopia; \\ *Corresponding Author: berhanu.tsegay@yahoo.com \\ ${ }^{2}$ Wachamo University, Hossana, Ethiopia; gebrey21@gmail.com
}

Received 7 October 2013; revised 9 November 2013; accepted 27 November 2013

Copyright (C) 2013 Berhanu Abraha, Gebremedhn Yohannes. This is an open access article distributed under the Creative Commons Attribution License, which permits unrestricted use, distribution, and reproduction in any medium, provided the original work is properly cited.

\section{ABSTRACT}

Salinity is considered as a major abiotic stress affecting germination, seedling growth and crop production in arid and semi-arid regions. Many techniques are used to improve tolerance to salinity. Priming is believed to be an effective solution that increases germination, plant growth and improve yield of several vegetables and crops under saline soil condition. The objective of this study was to see the effect of seed priming with $5 \mathrm{~g} / \mathrm{L} \mathrm{NaCl}$ on maize seedling growth exposed to five salinity levels under field conditions. Maize seeds were soaked in $5 \mathrm{~g} / \mathrm{L} \mathrm{NaCl}$ solution for $12 \mathrm{~h}$ at room temperature. Primed and unprimed seeds were sown in pots and were irrigated with saline solutions of five concentrations $(0,2,4,6$ and $8 \mathrm{~g} / \mathrm{l} \mathrm{NaCl})$. Each pot was irrigated with $200 \mathrm{ml}$ saline solution of the desired treatment in two days interval. Priming seeds with $\mathrm{NaCl}$ significantly $(P<0.05)$ improved growth of maize plants. As a result, fresh and dry weights of shoots and roots were improved. Seed priming alleviated the inhibitory effect of salt stress on seedling growth of maize under salt stress. Thus, seed priming with $5 \mathrm{~g} / \mathrm{l}$ $\mathrm{NaCl}$ could be used to improve early growth of Zea mays. Further, this study needs to be continued if performance of mature maize plants could also be improved and yield could be increased by sowing primed seeds in saline soils.

Keywords: Maize; Salinity; Seed Germination; Seed Priming; Seedling Growth

\section{INTRODUCTION}

Salinity affects $6 \%$ of the world's total land area which is approximately 800 million hectares [1]. Salinization is more spreading in irrigated lands because of inappropriate management of irrigation and drainage. Salinity has an adverse effect on seedling growth of several crops, by creating an osmotic potential in the rhizosphere of the plant. This inhibits the absorption of water or creates toxic effect due to $\mathrm{Na}^{+}$and $\mathrm{Cl}^{-}$to the roots and the whole crop [2]. Water uptake during the imbibition stage decreases and salinity induces an excessive absorption of toxic ions.

Seed priming or osmoconditioning is one of the physiological methods that improves seed performance and provides faster and synchronized germination. It is an easy, low cost and low risk technique and recently being used to overcome the salinity problem in agricultural lands. It entails the partial germination of seed by soaking in either water or in a solution of salts for a specified period of time and then re-drying them just before the radicle emerges [3]. This condition stimulates many of the metabolic processes involved with the early phases of germination and it has been noted that seedlings from primed seeds emerge faster, grow more vigorously and perform better in adverse conditions [4]. Some of the factors that affect seed priming response are solution composition and osmotic potential [5]. It has been shown that seed priming by $\mathrm{NaCl}$ could be used as an adaptive method to improve salt tolerance of seeds. A study conducted by Cayuela et al. [6] on tomatoes showed that seed priming improves seed germination, seedling emergence and growth under saline conditions.

Ethiopia is reported to possess over 11 million hectares of unproductive salt affected lands [7]. These areas 
are normally found in the arid and semi-arid lowlands, in the rift valley and other areas that are characterized by higher evapotranspiration rates. According to Hawando [8], salt-affected lands had increased from $6 \%$ to $16 \%$ of the total land area of Ethiopia and $9 \%$ of the population lived in those areas. According to this study, about 44 million ha (36\% of the country's total land areas) were potentially susceptible to salinity problems. Reclaiming back these salt affected areas and use them for agricultural production is very costly and time consuming.

Maize is one of the important crops in Ethiopia. It is consumed as main food with its crop residues and byproducts commonly fed to Livestock and used as source of fuel. Hence, Priming of maize seeds with $\mathrm{NaCl}$ could be important in improving the vegetative growth and yield of maize in areas that are potentially susceptible to salinity problems and totally unproductive salt affected wastelands. Such studies were not done before with maize in the Ethiopian agricultural landscapes at field conditions. Therefore, this study investigated the effect of priming on improving seedling growth of maize under different salinity levels in an open field conditions.

\section{MATERIALS AND METHODS}

The study was conducted in Bahir Dar city at Bahir Dar University (Peda campus). Bihar Dar city is the capital of the Amhara National Regional State in the Federal Democratic Republic of Ethiopia. It is located at $11^{\circ} 37^{\prime}$ $\mathrm{N}$ and $37^{\circ} 27^{\prime} \mathrm{E}$ on the southern side of Lake Tana with an altitude of 1801 meters above sea level. The annual temperature of the area ranges from a minimum average of $12.6^{\circ} \mathrm{C}$ to a maximum average of about $27.0^{\circ} \mathrm{C}$, and the mean annual rainfall is about $1406.98 \mathrm{~mm}$ [9].

\subsection{Seed Materialsand Priming}

Maize seeds (Melkasa 4) were obtained from the certified seed supplier of Ethiopian seed enterpriser (ESE) store located in Bahir Dar, Ethiopia.The seeds were surface sterilized (disinfected) with sodium hypochlorite $\left(\mathrm{Na}_{2} \mathrm{HCl}\right)$ solution for $3 \mathrm{~min}$ and then thoroughly washed for 5 min with distilled water. Subsequently the seeds were primed by soaking with $5 \mathrm{~g} / \mathrm{L} \mathrm{NaCl}$ solution for 12 $\mathrm{h}$, at room temperature and the ratio of seed weight to solution volume was 1:5 $(\mathrm{g} / \mathrm{ml})$. After priming, seeds were removed and washed with tap water and then rinsed three times in distilled water. Finally, seeds were left in air between two filter papers to re-dry to their original moisture level [10].

\subsection{Experimental Design}

The study was carried out from November 20, 2012 to April 16, 2013. Pot experiments were conducted in an open field, Bahir Dar University, to assess the growth (biomass and length) differences between primed and unprimed maize plants. The experimental design was two factors factorial, arranged in a completely randomized design, with four replications. The first factor was salinity stress due to salt solutions $(0,2,4,6$ and $8 \mathrm{~g} / \mathrm{L} \mathrm{NaCl})$ and the second factor was priming treatment $(\mathrm{NaCl}$ primed and unprimed seeds).

Forty white plastic pots, 20 for $\mathrm{NaCl}$ primed and 20 for unprimed control, were used (Supplement Figure 1). The pots were $40 \mathrm{~cm}$ in height and $35 \mathrm{~cm}$ in diameter. Ten seeds were sown in each pot at $2 \mathrm{~cm}$ depth and replicated four times. The pots were internally covered with black plastics to maintain constant temperature and drilled to have bottom water drainage and side aeration holes. The bottom of each pot was lined with drainage sand to keep the soil well drained and was filled with 1:3:1 of sand, local soil (the growth medium) and manure fertilizer, respectively. Each pot was irrigated with a $200 \mathrm{ml}$ of saline solution, at two days interval [11]. After, the $10^{\text {th }}$ day of seedling emergence, plants were thinned and maintained three per pot.

Shoot length was measured starting from one week old seedlings and done for four successive weeks. After five weeks from the start of the experiment (since seed germination), the total number of leaves of every plant in each pot was counted. Then plants were harvested carefully from soil surface and washed to remove the soil from their roots. Subsequently, root length, shoot and root fresh weights were determined immediately from each treatment. After all seedlings were dried in oven for $48 \mathrm{~h}$ at $70^{\circ} \mathrm{C}$, shoot and root dry weights were measured [12]. Finally, biomass difference, length variation and overall performance of the treatments were analyzed.

\subsection{Data Analysis}

All the data obtained from the experiments were subjected to an analysis of variance (Two way ANOVA) using SPSS (version 20.0) software and the difference between means were compared by Fisher's Post Hoc LSD tests $(P<0.05)$.

\section{RESULTS AND DISCUSSION}

\subsection{Effect of Priming on Shoot Length}

Analysis of variance showed that both salinity level and priming had significant effect on growth of shoot; root and leaf number (Table 1). But, the interaction between salinity and priming had significant impact on shoot length of the last two weeks only (Table 2). Salinity had significantly decreased the shoot length of maize in both unprimed and primed seeds (Figure 1). Though increasing salinity decreases rate of growth, shoot length 
Table 1. Analyses of variance of maize seedlings growth in five weeks at field conditions.

\begin{tabular}{lccccccc}
\hline Source & SL & RL & SFW & SDW & RFW & RDW & $\begin{array}{c}\text { Leaf } \\
\text { Number }\end{array}$ \\
\hline Priming & $1007.36^{*}$ & $2965.23^{*}$ & $238.24^{*}$ & $25.67^{*}$ & $271.83^{*}$ & $1.65^{*}$ & $16.9^{*}$ \\
$\begin{array}{c}\text { Salinity } \\
\text { Level }\end{array}$ & $2963.05^{*}$ & $2307.15^{*}$ & $868.59^{*}$ & $116.17^{*}$ & $283.96^{*}$ & $8.66^{*}$ & $71.78^{*}$ \\
$\begin{array}{c}\text { Priming } \\
\times \\
\text { Salinity } \\
\text { Level }\end{array}$ & $40.45^{*}$ & $132.19^{*}$ & $13.05^{*}$ & $2.15^{*}$ & $32.61^{*}$ & 0.27 & 0.65 \\
Error & 8.83 & 37.84 & 4.262 & 0.481 & 1.372 & 0.111 & 0.5 \\
\hline
\end{tabular}

*Significant at 0.05 significance level. Key: LS, shoot length; RL, root length; SFW, shoot fresh weight; SDW, shoot dry weight; RFW, root fresh weight; RDW, root dry weight.

Table 2. Analyses of variance of maize shoot length $(\mathrm{cm})$ in five weeks at field conditions.

\begin{tabular}{ccccc}
\hline \multirow{2}{*}{$\begin{array}{c}\text { Source } \\
\text { of Variance }\end{array}$} & \multicolumn{4}{c}{ Weeks After Planting } \\
\cline { 2 - 5 } & 2 & 3 & 4 & 5 \\
\hline Priming & $161.20^{*}$ & $337.91^{*}$ & $495.80^{*}$ & $736.97^{*}$ \\
Salinity Level & $1367.32^{*}$ & $4812.59^{*}$ & $9358 . .06^{*}$ & $11737.26^{*}$ \\
Priming $\times$ Salinity Level & 34.66 & 98.73 & $142.37^{*}$ & $168.14^{*}$ \\
Error & 7.68 & 10.06 & 13.20 & 15.474 \\
\hline
\end{tabular}

*Significant at 0.95 confidence level.



Figure 1. Effect of different salinity levels on shoot length of primed and unprimed seeds of maize in five weeks of growth time (mean \pm stand. Dev.).

was significantly improved in the primed compared to the unprimed seeds (Figure 1). The increment of shoot growth $(\mathrm{cm})$ from week 2 to week 5 in primed seeds (24.503) was higher compared to the unprimed seeds (19.933). Majority of the seedlings grown from unprimed seeds and irrigated with $8 \mathrm{~g} / \mathrm{L}$ had died.

Reduction in unprimed shoot growth as a result of salt stress has been reported by many studies on different plant species $[11,12]$. These reductions might be due to both osmotic and specific ionic effects on seedlings growth [13]. Similarly, toxic ion accumulation $\left(\mathrm{Na}^{+}\right.$and $\mathrm{Cl}^{-}$) negatively affect plant metabolism.

The faster shoot growth of maize plants from primed seeds were the result of higher capacity of osmotic adjustment because plants from primed seeds have more $\mathrm{Na}^{+}$and $\mathrm{Cl}^{-}$in roots and leaves than plants from nonprimed seeds. This might have helped to increase water absorption and turgor pressure that speed up growth parameters [14].

\subsection{Effect of Priming on Root Length}

Mean of maize root growth was significantly $(P<0.05)$ affected by salinity and priming (Table 1). The effect of the interaction between salinity and seed priming also significantly reduced root length at $P<0.05$. This reduction was significant in all saline media (Figure 2). The decrements were highly noticeable in root lengths of unprimed seeds in comparison to the primed ones. An increase of root length in primed seeds as compared to the unprimed could be a result of embryo cell wall extensibility. Seed priming increase the free radical scavenging enzymes (peroxidase, catalase and superoxide dismutase) to improve plant viability and strength under salinity stress [15]. The pre-soaking of seeds allows the hydration of membranes and proteins, and the initiation of various metabolic systems [16]. This is possibly due to balanced $\mathrm{Na}^{+} / \mathrm{K}^{+}$ratio that are important for the adjustment of cell osmoregulation, turgor maintenance, uptake of water and essential minerals like $\mathrm{P}, \mathrm{K}, \mathrm{Ca}$ and $\mathrm{N}$ [17].

\subsection{Shoot and Root Fresh and Dry Weights $\left(g \cdot\right.$ plant $\left.^{-1}\right)$}

Growth of maize in pots in the open field showed significant $(P<0.05)$ effect of salinity level and seed priming on shoot fresh and dry weights (Table 3). The interaction of seed priming and salinity level also significantly $(P<0.05)$ affected the shoot fresh and dry weights. As salinity level increase, the reduction in growth increased proportionally (Table 3). But the inhibitory effect was more increased in weights recorded from unprimed seeds in relation to primed seeds (Figures 3(a)(d)).

Maize roots are rapidly affected by salinity because they are the first organ to be exposed to salinity. They are in direct contact with soil, absorbing mineral solution from soil to the rest of the plant. As salinity increase cell division of the root apex decrease and the cells become smaller in size [18]. The toxic effect of sodium at high salt levels and physical damage to roots decreased their ability to absorb water and nutrient which caused strong reduction in photosynthesis, enzymatic process and pro- 
Table 3. Means comparison of the shoot and root fresh and dry weights at different salinity levels.

\begin{tabular}{cccccc}
\hline Salinity (g/L) & SFW (g) & SDW (g) & RFW (g) & RDW (g) & LN \\
\hline 0 & $29.692^{\mathrm{a}}$ & $9.929^{\mathrm{a}}$ & $16.191^{\mathrm{a}}$ & $2.539^{\mathrm{a}}$ & $9.125^{\mathrm{a}}$ \\
2 & $13.746^{\mathrm{b}}$ & $4.867^{\mathrm{b}}$ & $8.598^{\mathrm{b}}$ & $1.231^{\mathrm{b}}$ & $5.875^{\mathrm{b}}$ \\
4 & $10.218^{\mathrm{c}}$ & $2.875^{\mathrm{c}}$ & $5.719^{\mathrm{c}}$ & $0.505^{\mathrm{c}}$ & $3.875^{\mathrm{c}}$ \\
6 & $6.5^{\mathrm{d}}$ & $1.174^{\mathrm{d}}$ & $2.776^{\mathrm{d}}$ & $0.111^{\mathrm{d}}$ & $2.5^{\mathrm{d}}$ \\
8 & $2.702^{\mathrm{e}}$ & $0.388^{\mathrm{e}}$ & $1.037^{\mathrm{e}}$ & $0.028^{\mathrm{e}}$ & $1.625^{\mathrm{e}}$
\end{tabular}

*Means with different letters in each column are significantly different at 0.05 (post hoc LSD test).

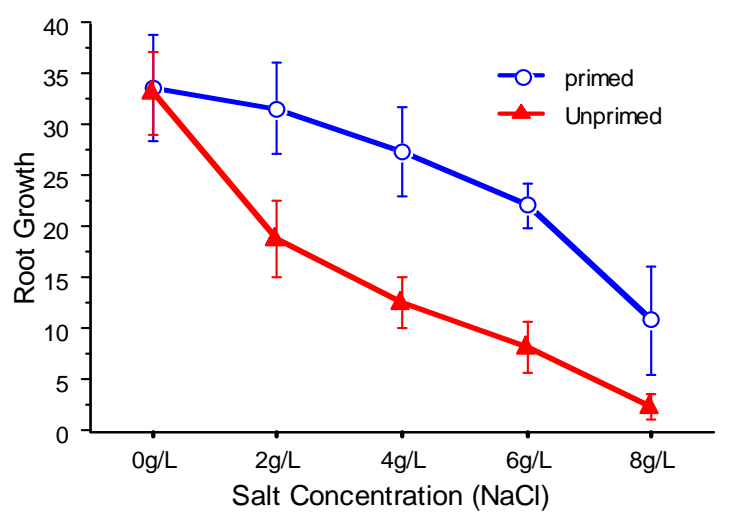

Figure 2. Effect of different salinity levels and seed priming on root length of maize seedlings under field condition (mean \pm st. dev.).

tein synthesis. This resulted in limited growth and poor leaf area development. Similarly under saline conditions, depletion of $\mathrm{O}_{2}$ removes the plants' primary energy source and accumulates high levels of internal ethylene that cause the inhibition of root elongation [13].

In the same way to the roots, shoot dry weight of maize seeds was reduced significantly with increased salinity levels (Table 3); with more extent in unprimed seeds compared to the primed seeds (Figure 3(b)).

Halopriming increases the superoxide dismustase activity of plants under saline conditions [19]. Bakht et al. [20] reported that, the increment of antioxidant enzymatic activity in various wheat cultivars due to halopriming was a key component in tolerance against salt stress. Afzal et al. [10] also observed that priming-induced salinity tolerance was linked with improved seedling vigor, metabolism of reserves, enhanced $\mathrm{K}^{+}, \mathrm{Ca}^{2+}$ accumulation and reduced $\mathrm{Na}^{+}$accumulation in wheat plants. Toxic ion accumulation $\left(\mathrm{Na}^{+}\right.$and $\left.\mathrm{Cl}^{-}\right)$negatively affect plant metabolism. This could adversely affect plant fresh and dry weights. In this work, the root fresh and dry weights of primed maize seedlings were increased significantly in comparison to the unprimed seeds. The

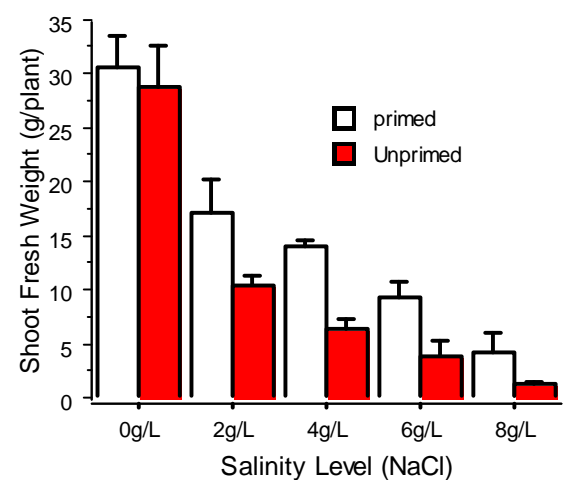

(a)

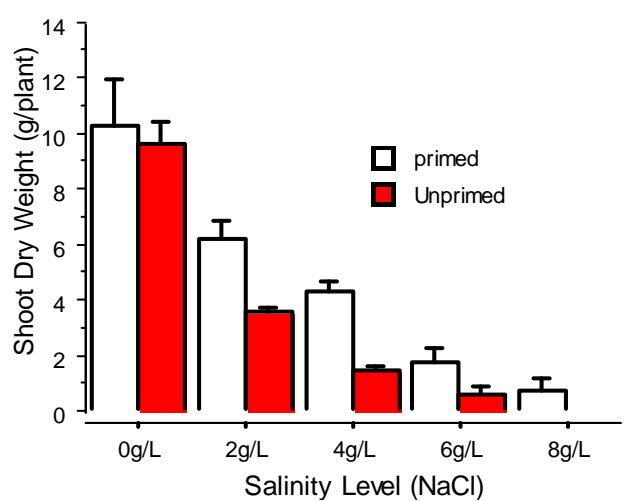

(b)

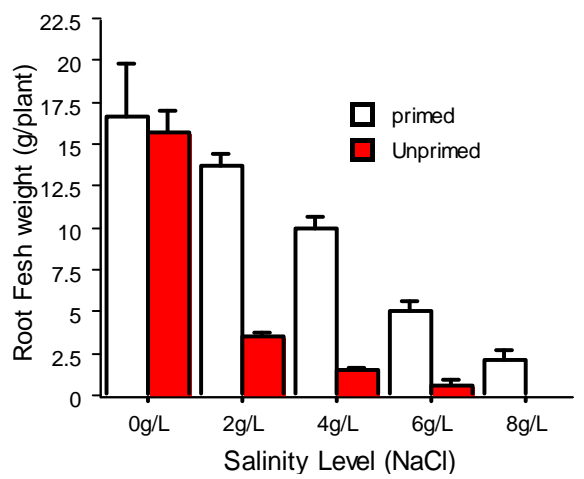

(c)

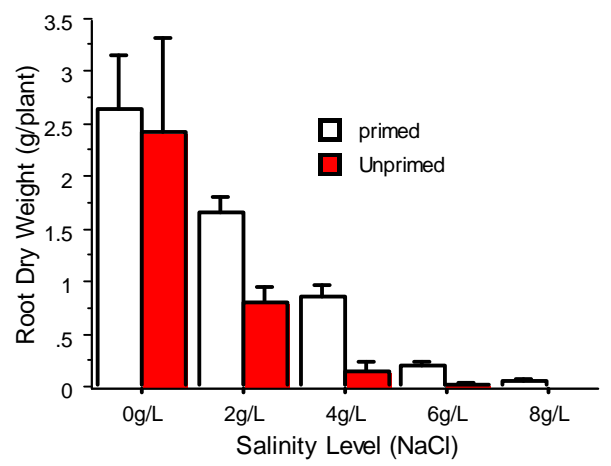

(d)

Figure 3. Effect of different salinity levels and seed priming on shoot and root fresh/dry weights of maize (a) shoot fresh weight (b) shoot dry weight (c) root fresh weight (d) root dry weight at field conditions (Mean \pm st. dev.). 


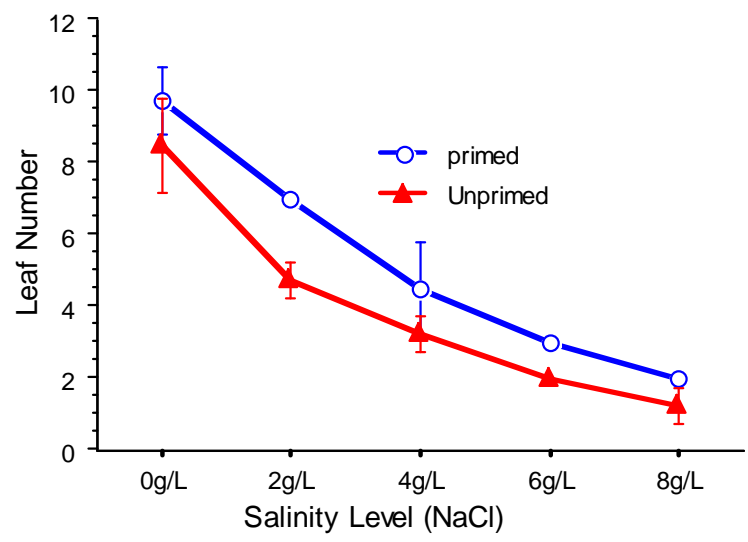

Figure 4. Effect of different salinity levels on leaf number of primed and unprimed maize plants grown for five weeks at field conditions (mean \pm st. dev.).

higher salinity levels reduced root weight especially in the unprimed group (Figures 3(b) and (d)).

\subsection{Leaf Number}

Based on the results of the variance of analysis, priming and salinity levels significantly $(P<0.05)$ affected leaf number of each maize plant grown from both primed and unprimed seeds. However, the interaction of priming and salt concentration levels did not have a significant $(P$ $<0.05$ ) difference (Table 1). Data presented in Table 3 shows that, increasing salinity level reduced number of leaves per plant. But, the rate of reduction was less pronounced in the primed plants than the unprimed ones (Figure 4). Primed seeds had more leaves when compared with unprimed treatments. Leaves of plants grown in pots irrigated with $6 \mathrm{~g} / \mathrm{L}$ and $8 \mathrm{~g} / \mathrm{L}$ totally died and dried out.

Seedlings grown in saline solutions had fewer, smaller and thicker leaves. The toxic effect of sodium at high salt levels and physical damage to roots decreased their ability to absorb water and nutrients which caused poor leaf development and noticeable reduction in photosynthesis, enzymatic process and protein synthesis which resulted in weak plant growth [13].

\section{CONCLUSION}

Salinity inhibits early seedling growth of maize seeds. Priming is an effective method to meet the demands of farmers on salinity stressed crop fields. The better performance of maize from primed seeds in this experiment is an illustrative for the necessity of priming seeds before sowing in saline soils. Further study is also required to investigate the effects of seed priming on the late growth and yield stages of maize. Additional advanced research is needed to explore priming induced alteration of physiological and biochemical attributes both at seed and whole plant levels in maize.

\section{REFERENCES}

[1] FAO (2012) Land and plant nutrition management service. http://www.fao.org/ag/agl/agll

[2] Khajeh-Hosseini, M., Powell, A.A. and Bimgham, I.J. (2003) The interaction between salinity stress and seed vigor during germination of soybean seeds. Seed Science Technology, 31, 715-725.

[3] Neto, A.D. and Tabosa, J.N. (2000) Salt stress in maize seedlings: I. Growth analisys. Revista Brasileirade Engenharia agrícola e Ambiental, 4, 159-164.

[4] Cramer, G.R. (2002) Sodium-calcium interactions under salinity stress in Läuchli A, Lüttge salinity. Envirnomentplants, 4, 205-227.

[5] Chinnusamy, V., Jagendorf, A. and Zhu, J.K. (2005) Understanding and improving salt tolerance in plants. Crop Science, 45, 437-448. http://dx.doi.org/10.2135/cropsci2005.0437

[6] Cayuela, E., Perez-Alfocea, F., Caro, M. and Bolarin, M.C. (1996) Priming of seeds with $\mathrm{NaCl}$ induces physiological changes in tomato plants grown under salt stress. Physiological Plantarum, 96, 231-236. http://dx.doi.org/10.1111/j.1399-3054.1996.tb00207.x

[7] Plant Genetic Resource Center (PGRC) (1996) Ethiopia: Country report to the FAO international technical conference on plant genetic resources. Plant Genetic Resource Center (PGRC), Addis Ababa.

[8] Hawando, T. (1994) Desertification in Ethiopian highlands. Norwegian Church Aid, Addis Ababa.

[9] National Metrological Agency Bahir Dar Branch Office (NMABDBO) (2013) Annual report. NMABDBO, Bahir Dar.

[10] Afzali, R.S., Basra, S.M.A. and Murtaza, G. (2008) Halopriming improves vigor, metabolism of reserves and ionic contents in wheat seedlings under salt stress. Plant Soil Environment, 54, 382-388.

[11] Ahmadvand, G., Soleimani, F., Saadatian, B. and Pouya, M. (2012) Effects of seed priming on germination and emergence traits of two soybean cultivars under salinity stress. International Research of Applied and Basic Sciences, 3, 234-241.

[12] Elouaer, M.A. and Hannachi, C. (2012). Seed priming to improve germination and seedling growth of safflower (Carthamus tinctorius) under salt stress. EurAsian Journal of Biosciences, 6, 76-84. http://dx.doi.org/10.5053/ejobios.2012.6.0.9

[13] Akram, M., Ashraf, M.Y., Ahmad, R., Waraich, E.A., Iqbal, J. and Mohsan, M. (2010) Screening for salt tolerance in maize (Zea mays L.) hybrids at an early stage. Pakistan Journal of Botany, 42, 141-151.

[14] Nasim, M., Qureshi, R., Aziz, T., Saqib, M., Nawaz, S., Sahi, S.T. and Pervaiz, S. (2008) Growth and ionic composition of salt stressed Eucalyptus camaldulensis and Eucalyptus teretcornis. Pakistan Journal of Botany, 40, 799-805. 
[15] Shafi, M., Bakht, J., Raziuddin, M. and Zhang, G. (2009) Effect of cadmium and salinity stresses on growth and antioxidant enzymes activity of wheat genotypes. Bulletin of Environmental Contamination and Toxicology, 82, 772-776. http://dx.doi.org/10.1007/s00128-009-9707-7

[16] Okcu, G., Demir, M. and Ataka, M. (2005) Effects of salt and drought stresses on germination and seedlings growth of pea (Pisum sativum L.) Turkish Journal of Agriculture, 20, 237-242.

[17] Nawaz, A., Amjad, M., Jahangir, M.M., Khan, M.S., Cui, H.W. and Hu, J. (2012) Induction of salt tolerance in tomato (Lycopersicon esculentum Mill.) seeds through sand priming. African Journal of Crop Science, 6, 1199-1203.
[18] Tuna, A.L., Kaya, C., Dikilitas, M. and Higgs, D. (2008) The combined effects of gibberellic acid and salinity on some antioxidant enzyme activities, plant growth parameters and nutritional status in maize plants. Environmental and Experimental Botany, 62, 1-9. http://dx.doi.org/10.1016/j.envexpbot.2007.06.007

[19] Afzal, I., Ashraf, S., Qasim, M., Basra, S.M.A. and Shahid, M. (2009) Does halopriming improve germination and seedling vigour in marigold? Seed Science Technology, 37, 436-445.

[20] Bakht, J., Shafi, M. and Shah, R. (2011) Response of maize cultivars to various priming sources. Pakistan Journal of Botany, 43, 205-212. 


\section{APPENDIX}


Supplement Figure 1. Effects of salt stress and seed priming on shoot growth of maize seedlings at field conditions. (a) unprimed and (b) primed. 